\title{
THE MEDIATING ROLE OF RISK PERCEPTION AMONG COGNITIVE BIASES TOWARDS DECISION TO START A NEW VENTURE
}

\author{
Maheen Butt, Nadia Jamil, Rabia Nawaz \\ Mohammad Ali Jinnah University, \\ PECHS Block 6, Karachi, Pakistan \\ E-mail address: Nad_jamil@yahoo.com, micke_7_48@hotmail.com, \\ Rabia.nawaz10@yahoo.com
}

Keywords: Cognitive biases, Risk perception \& Decision to start a new venture

\begin{abstract}
The Objective of the study is to investigate the relationship of overconfidence bias and illusion of control bias towards the start of new venture, with the mediating role of risk perception in context of Pakistan. To understand the relationship, this study developed and tested hypothesis by correlation and regression analysis. This study's sample consisted of 170 students pursuing a Masters of Business Administration. The students' responses to a survey based on a case study regarding a decision to start a venture were examined. This study found illusion of control and risk perceptions have significant effect on decision to start new venture. Conversely, overconfidence bias has insignificant relationship with decision to start new venture. The positive and negative impact of biases and perceiving low levels of risk suggest the importance of exploring the area of venture formation. As this study has incorporated two biases but many other biases should also be considered that effect human decision making process like self-efficacy, availability heuristics, law of small numbers and escalation of commitment.
\end{abstract}

\section{INTRODUCTION}

Business is full of adventure. Being the main stream line of financial and economic system many businesses shuts down and comes new daily. For sure, such innovation of new businesses is also named as entrepreneurship and its decisions to become in action, is also associated with stakeholder cognition and emotions. Examining venture creation decisions from a perspective of cognitive biases and perceptions of entrepreneurs report the critical role of cognitive biases in entrepreneurial decision making (Robinson \&. Marino, 2013). The nature of entrepreneurial contexts and processes indicates the presence of cognitive biases such as overconfidence among entrepreneurs (Baron, 1998; Cassar, 2010), and it is acceptable that new entrepreneurs tend to be overconfident about their expectations (Cassar, 2010). A body of research emphasizes the importance of overconfidence as a significant cognitive construct for entrepreneurial research. Thus, an entrepreneurial cognition perspective emerges as a meaningful extension of cognitive theory (Robinson \& Marino, 2013). Cognitive theory involves heuristics and cognitive biases, which may cause individuals to involve in less than rational decision-making (Baron, 1998).

As the decision to start a new business involves risk, an individual who has a tendency to take risk would form a new venture as compared to someone who is averse in taking risk (Shaver and Scott, 1991). Forlani and Mullins (2000) investigated perceived risk in their study and found significant association with biases regarding investors and especially entrepreneurs. When ventures have same levels of investment and the expected values of returns then they are chosen on the basis of differences in risk propensities among entrepreneurs. Thus an individual who is moderate in risk taking and risk averse survives more in business (Caliendo, Fossen \& Kritikos, 2010). Conversely, Gartner and Liao (2012) argued that individual's risk taking propensity doesn't seem to affect the likelihood that they will successfully start a business. Entrepreneur do take risk but their "risk takers" aspect is not because of the characteristic of their personality.

Kickul, Gundry, Barbosa, and Whitcanack (2009) stated that cognitive style plays an important role in evolvement of entrepreneurial intentions and the new venture creation process. 
Further, Carolis and Saparito (2006) elaborated that any of the cognitive biases influence an entrepreneur to undervalue the amount of risk linked with a specific new venture creation, so that individuals who are overconfident treat their assumptions as fact and may believe that certain decisions are less risky than they really are. Therefore, the more overconfident individuals tend to perceive lower risk, and are more inclined to decide to create a new venture relative to the person who is less confident (Robinson \& Marino, 2013).

The illusion of control bias describes the tendency of decision makers to overestimate their control over outcomes of an event; typically the entrepreneurs overemphasize their skills that would increase the performance in situations where chance plays a larger role as a factor in decision making (Langer 1975). Entrepreneurs may be more prone to illusion of control than other individuals (Duhaime \& Schwenk, 1985; Simon, Houghton \& Aquino, 2000). Individuals exhibiting an illusion of control will underestimate risk associated with a new venture because they believe their skills can prevent negative outcomes ( Keh, Foo, \& Lim, 2002).

The Objective of the study is to investigate the relationship of overconfidence bias and illusion of control bias towards the start of new venture, with the mediating role of risk perception in context of Pakistan. Antonczyk and Salzmann (2012) suggested that culture plays an important role in venture capital activity. Some cultures are more encouraging for venture formation as compared to others. Individualisms positively associated with venture capital activity and uncertainty avoidance has negative effect on venture capital.

Individuals in different cultures are subject to different behavioral biases which lead to different risk perceptions. In under developed country, the relationship among cognitive biases to start a new venture with mediator of perceptual risk is less investigated (Bhatnagar, 2007). This study explores, to what extent relationship exists between cognitive biases and perceived risk. Secondly, to what extent perceived risk is significant with new venture start. Thirdly, to what extent cognitive biases are insignificant with starting a new venture, as limited literature is available in context of Pakistan.

\section{LITERATURE REVIEW}

\section{Decision to start a New Venture}

The initial achievement of a business is its birth (Gelderen, Thurik and Bosma, 2005). Researchers have examined the impact of numerous factors that influence on venture formation including personality traits (Frank \& Korunka, 2007), culture and gender (Shinnar, Giacomin, \& Janssen, 2012). Even with the high risk complex situation; thousands of people decide to start ventures. Risks represent the possibility for loss (Forlani and Mullins, 2000). Researches revealed that entrepreneurs do not have a high risk tendency, that is, a great will to significantly take risks (Lévesque and Minniti, 2006).

As stated by Parhankangas and Hellström (2007) risk lies at the heart of the entrepreneurial development. Risk preference plays an important role on entrepreneurial intentions to start a new venture (Barbosa et. al., 2007; Hormiga and Cruz 2012). Hayward et. al., (2006) several new ventures are formed in the sleuth of high venture failure rates, overconfident entrepreneurs are motivated to start ventures, and then doing on such confidence when determining by what means to assign possessions in their ventures. Finally, two thirds of high technology entrepreneurs declared they were not taking any risk (Corman, Perles and Vancini 1988). Even though these readings dedicated on performing entrepreneurs, it logically surveys that perceiving low levels of risk may influence the individuals' opening decision to start ventures. 
H1: Perceiving a lower level of risk is associated with the decision to start a venture.

\section{Overconfidence bias}

Overconfidence bias is more common among entrepreneurs as compared to the others. Entrepreneurial over confidence bias is caused when individual factors (previous experience, personal optimism, self-efficacy, data limitations, environmental pressure and availability heuristic) combined with environmental situation (Farsi, Nouri, Kafeshani, \& Toghraee, 2014). Entrepreneurs are more intuitive as compared to non-entrepreneurs. Cognitive heuristics facilitate fast decision making which reduces risk perception which enables entrepreneur to follow their risky idea. Analytical cognitive style increases the chance of the enterprise success but decreases the likelihood of creating a business (Barbosa, Gerhardt \& Kickul, 2007).

However, Forbes (2005) narrated that decision comprehensiveness increases overconfidence. In decision making situations individuals get confident by considering more information but that more information does not guarantee decision accuracy. Overconfidence is someone's prediction related to the event with excessive certainty. Further Simon and Houghton (2003) stated that, managers who are overconfident that they will achieve certain success introduce pioneering rather than incremental products. Overconfidence takes place in actual strategic decision situations that are ill-structured. In the risky situations the chances of making decisions on the basis of overconfidence increases. Zacharakis and Shepherd (2001) analyzed that due to overconfidence bias venture capitalists rely on limited information and do not haunt for more information which results in making wrong investment decisions and losing available opportunities which should be grasped. In order to increase the decision accuracy the use of counterfactual thinking, the humbling effect and decision aids techniques can be used which reduces overconfidence bias. This bias diminishes an individual's perception towards the level of risk associated with new venture formation (Simon et. al., 2000; Zacharakis \& Shepherd 2001; Carolis, \& Saparito, 2006). Therefore, it is hypothesized that:

$\mathbf{H}_{2}$ : Overconfidence bias is positively associated with decision to start a new venture.

\section{Illusion of Control bias}

Sometimes underestimating the chance of controlling a situation results in incurring more costs than overestimating that chance. Illusion of control arises where people incorrectly assign control to events in which outcomes result from chance, but the attribution is based on rational processes (Harris \& Osman, 2012). Both situational (personal involvement, familiarity, foreknowledge of the desired outcome and success at the task) and person-based factors (mood and need for control) influence whether or not people will overestimate their control (Thompson, 1999). Emotive reactions play an important role on the cognitive process during decision making under risky situation. Joy and happiness encourages people's perception of sense of security and control over the environment, prepare them to adopt risky decisions (Maldonato \& Dell'Orco, 2011). A study by Meissner and Wulf (2014) pointed out that, in strategic decisions under uncertainty external advice seeking reduces the illusion of control bias, as compared to internal advice seeking. External advisors provide more information to decision makers whereas; internal advice increases certainty in one's own decisions which results in undervaluation of alternative perspectives. More cost is incurred in order to seek external advice whereas; internal advice can easily be accessed. Proper cost-benefit considerations of seeking advices from these two sources can reduce the illusion of control and positively affect organizational performance. Fellner (2009) stated that illusion of control results in underestimation of risk while making investment decisions. An illusion of control bias is negatively associated with the risk perception in order to start a new venture (Kannadhasan, Aramvalarthan, \& Kumar, 2014; Simon et al 2000). Hence it is hypothesized that: 
$\mathbf{H}_{3}$ : Illusion of control bias is positively associated with decision to start a new venture

Mediating role of Risk Perception:

The study also originates differences among the individuals in starting the venture yet they evaluated the identical venture. It is due to the influence of cognitive biases on risk perception as well as new venture creation. It indicates that take in a lower level of risk is associated with the new venture decision. Entrepreneur when develops positive attitude towards his business future they underestimate environmental uncertainty. Which decrease their risk perception related to the new venture formation (Brockman, Becherer \& Finch 2006; Keh et. al., 2002; Chen and Dong 2007; Farsi et al, 2014). Risk perceptions mediates the relationship between cognitive biases and venture creation decisions (Robinson \& Marino 2013; Iacobucci and Duhachek (2003); Simon et. al., 2000; Kannadhasan et.al., 2014). Thus, it is stated that:

$\mathbf{H}_{4}$ : The relationship between overconfidence and the decision to start a venture is fully mediated by risk perception.

$\mathbf{H}_{5}$ : The relationship between illusion of control and the decision to start a venture is fully mediated by risk perception.

\section{Theoretical framework}

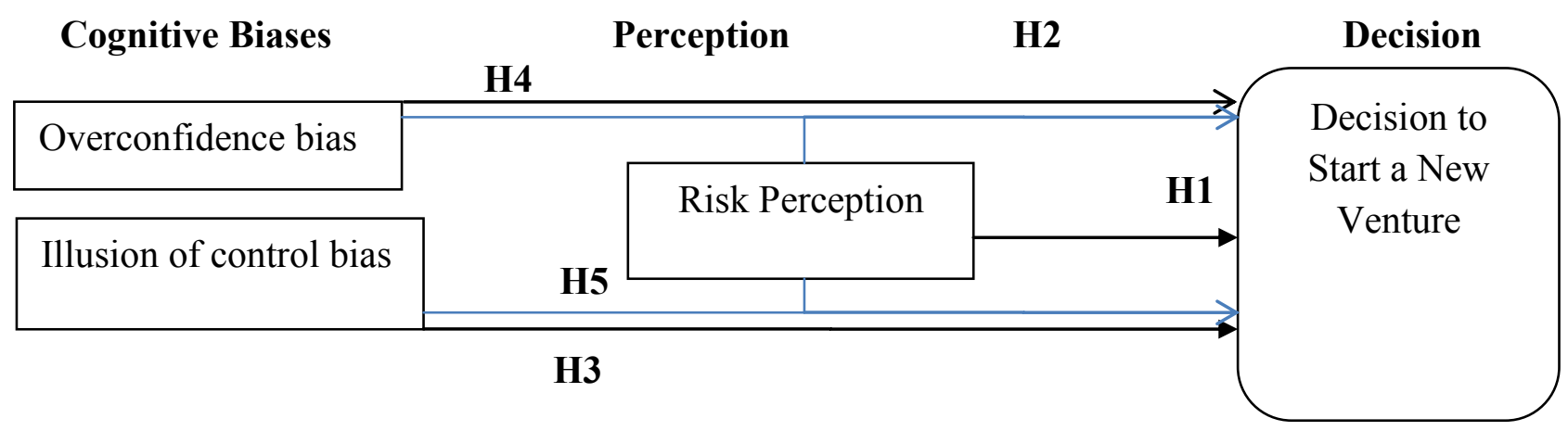

\section{RESEARCH METHODOLOGY Instrumentation}

Primary data was collected through the structured close ended questionnaire adopted from "Cognitive Biases, Risk Perception, and Venture formation: How individuals decide to start companies" by Mark Simon, Susan M. Houghton \& Karl Aquino in 1999.

There are total 15 questions in the questionnaire. The questionnaire comprised of two sections. First section collected the respondents' demographic data, such as gender, age \& education level. The second part gathered data from the respondents about the Decision to start a new venture.

\section{Population and Sample Size}

Convenience sampling technique has been used for the collection of data because of time constraint. The data was collected from Islamabad and Rawalpindi, by means of personal and online distribution of questionnaires.

The sample was consisting of decision to start a new venture by students. Total of 250 was questionnaires were distributed out of 250 only 180 are received, from which 170 are useable. Hence response rate $68 \%$. The respondents consist of $44.4 \%$ ( 80) male and females (80) $55.5 \%$. The mean age of respondents was between 18-35. Education level range from MBA, PHIL \& PHDs Students. From which with $8.6 \%$ of the respondents was having PHDs degree, $50 \%$ MS/M.PHIL level, $41.4 \%$ MBAs

\section{Measurement of variables}

All items scale of the variable was adopted from prior studies where they had been tested for reliability.7 validity. A 5 point like scale having a range from strongly disagrees to strongly agree was used. 


\section{Analysis}

We used two regression analyses to test the direct effects suggested in Hypotheses 1-3. Model 1 tested $\mathrm{H} 1$ by regressing the decision to start a new venture on risk perception. Model 2 examined H2 \& H3 by regressing risk perception on the cognitive biases. To prove Hypotheses $4 \& 5$, the analysis had to meet the four conditions needed to establish that a mediated relationship exists (Baron and Kenney 1986).

Regression model 2, which tested Hypotheses $2 \& 3$, also tested the first of these mediation conditions, namely, that the independent variables affected the mediator. We used a third regression model to examine if the independent variables affected the dependent variable, which is the second condition needed to establish mediation. In other words, the effect of cognitive biases on the decision to start a new venture must decrease when risk perception is included in the equation.

TABLE 1 Means, Standard Deviations, and Correlations among Measures of Biases, Risk, and the Decision to Start a Venture

\begin{tabular}{|llllll|}
\hline Mean & SD & 1 & 2 & 3 \\
\hline
\end{tabular}

1. Decision to start a venture

2. Risk perception

3. Overconfidence

4. Ill. of control

$3.38 \quad 1.09$

$3.11 \quad 0.68$

$6.49 \quad 2.85$

$3.10 \quad 0.74$

$\begin{array}{ll}-0.58 * * & \\ -0.02 & 0.03 \\ 0.28 * * & 0.20 *\end{array}$

$* p<0.05 ; * * p<0.01 ; * * * p<0.001$.

Table 1 presents the means, standard deviations, and correlations among the study variables.

Table 2 contains the results of the four regression models used to test Hypotheses $1-5$. The results of model $1(\mathrm{R} 2=0.33, \mathrm{p}<0.001)$ support Hypothesis 1 . There is a significant negative relationship between risk perception and the new venture decision $(\beta=0.58, p<0.001)$. Model 2 which tested Hypotheses $2 \& 3$, found that mutually the biases described a significant ratio of the variance in risk perception $(\mathrm{R} 2=0.10, p<0.001)$. Hypotheses 3 , the illusion of control $(\beta=-0.19, p<0.01)$ lowered risk perception. Hypotheses 2 was not supported, conversely, as there was no significant relationship between overconfidence and risk perception $(\beta=-0.01$, NS). Hypotheses $2 \& 3$ discovered whether risk perception mediated the effects of cognitive biases on the decision to start a venture. In calculation to testing Hypotheses $2 \& 3$, model 2 also tested the first mediation condition: a significant relationship between the mediator and the independent variables. As stated, the illusion of control lowered risk perception. In compare overconfidence did not lower risk perception so it cannot affect the decision to start a new venture indirectly through risk perception. Model 3 accounts the results for the second condition, a relationship between the independent variables and the decision to start a new venture. The overall equation was significant $(\mathrm{R} 2=0.15$, $p<0.001)$, and the illusion of control $(\beta=0.29, p<0.001)$. But overconfidence bias was not significantly related to the decision to start a new venture $(\beta=0.00, \mathrm{NS})$.

TABLE 2 Results of Regressions: The Relationships among Biases, Risk-taking, and the Decision to Start a Venture

\begin{tabular}{lccc}
\hline & $\begin{array}{c}\text { Model 1 } \\
\text { Decision to start } \\
\text { a new Venture }\end{array}$ & $\begin{array}{c}\text { Model 2 } \\
\text { Risk } \\
\text { Perception }\end{array}$ & $\begin{array}{c}\text { Model 3 } \\
\text { Decision to start } \\
\text { a new Venture }\end{array}$ \\
\hline Risk perception & $-0.58^{* * *}(-9.60)$ & & \\
$\begin{array}{l}\text { Overconfidence } \\
\text { Ill. of control }\end{array}$ & & $-0.01 \quad(-0.13)$ & $0.00 \quad(0.00)$ \\
F statistic & $23.27^{* * *}$ & $-0.19^{* *}(-2.63)$ & $0.29^{* * *}(3.81)$ \\
R2 & 0.33 & $0.63^{* * *}$ & $4.97 * * *$ \\
Adj. R2 & 0.32 & 0.10 & 0.15 \\
\hline
\end{tabular}

$* p<0.05 ; * * p<0.01 ; * * * p<0.001$. 
As a result, Hypotheses 3 only partially supported. The analysis provided no support for Hypothesis 2 because overconfidence was not significant in any of the equations.

\section{CONCLUSION}

This study has incorporated the perceptions related to the overconfidence, illusion of control, risk perception and decision to start a new venture in Asian context. The results of the study are supported by the cognitive theory. As risk is involved in order to start any venture and entrepreneurs do not invest in risky ventures with their will. Entrepreneur when develops positive attitude towards his business future, they underestimate environmental uncertainty. Which decrease their risk perception related to the new venture creation. Cognitive biases help in reducing this risk perception. Our study has showed strong influence of illusion of control as compared to the overconfidence bias on new venture formation. Illusion of control arises in venture formation where people incorrectly assign control to the success of business, whereas, outcomes result from chance. This may be due to the reason entrepreneur don't consider competitors 'response or either competitors are outside their control domain (Kerin, Varadarajan, Peterson, 1992). Overconfidence bias doesn't directly affect decision to start a new venture. cognitive biases influence an entrepreneur to undervalue the amount of risk linked with a specific new venture creation, so that individuals who are overconfident treat their assumptions as fact and may believe that certain decisions are less risky than they really are. Our results are in accordance to the Simon et. al. (2000); Kannadhasan et. al. (2014).

Practical implication of the study is that in decision making process risk perception should be given very importance. During the decision making process counterfactual thinking, humbling effect and group decision making process can facilitate reducing cognitive biases and correct estimation of risk (Zacharakis and Shepherd, 2001).

\section{Limitation}

As this study has incorporated two biases but many other biases should also be considered that effect human decision making process like self-efficacy, availability heuristics, law of small numbers and escalation of commitment. Future researches should introduce additional factors that may directly or indirectly affect risk perception in predicting the decision to start a venture as exposure to role models. The future studies may incorporate the impact of culture (Antonczyk and Salzmann, 2012), gender (Shinnar, Giacomin, \& Janssen, 2012) and economy on venture formation (Bhatnagar, 2007).

\section{References}

[1] Antonczyk, R. C., \& Salzmann, A. J. (2012). Venture capital and risk perception. Zeitschrift für Betriebswirtschaft, 82(4), 389-416.

[2] Barbosa, S. D., Gerhardt, M. W., \& Kickul, J. R. (2007). The role of cognitive style and risk preference on entrepreneurial self-efficacy and entrepreneurial intentions. Journal of Leadership \& Organizational Studies, 13(4), 86-104.

[3] Baron, R. A. (1998). Cognitive mechanisms in entrepreneurship: why and when entrepreneurs think differently than other people. Journal of Business Venturing, 13, 275-294.

[4] Bhatnagar, J. (2007). Talent management strategy of employee engagement in Indian

[5] ITES employees: key to retention. Employee Relations, 29(6), 640-663.

[6] Brockman, B. K., Becherer, R. C., \& Finch, J. H. (2006). Influences on an entrepreneur's perceived risk: The role of magnitude, likelihood, and risk propensity. Academy of Entrepreneurship Journal, 12(2), 107. 
[7] Caliendo, M., Fossen, F. \& Kritikos, A. (2010). The impact of risk attitudes on entrepreneurial survival . Journal of Economic Behavior \& Organization 76, 45-63

[8] Carolis, D. \& Saparito, P. (2006). Social Capital, Cognition, and Entrepreneurial Opportunities: A Theoretical Framework. Entrepreneurship Theory and Practice, 1042-2587.

[9] Cassar, G. (2010). Are individuals entering self- employment overly optimistic? an empirical test of plans and projections on nascent entrepreneur expectations. Strategic Management Journal, 31(8), 822-840.

[10]Chen Z, Dong J (2007) Risk perception and entrepreneur's decision to start a venture: An empirical study from Optical Valley of China (Wuhan). In: Wuhan (ed) The sixth wuhan international conference on E-Business-innovation management track.

[11]Corman, J., Perles, B., \& Vancini, P. (1988). Motivational factors influencing high-technology entrepreneurship. Journal of Small Business Management,26(1), 36.

[12]Duhaime, I. M., \& Schwenk, C. R. (1985). Conjectures on cognitive simplification in acquisition and divestment decision making. Academy of Management Review, 10(2), 287295.

[13]Farsi, J. Y., Nouri, P., Kafeshani, A. A., \& Toghraee, M. T. (2014). Identifying the Main Factors Influencing the Formation of Overconfidence Bias in Entrepreneurs: A Qualitative Content Analysis Approach. International Journal of Academic Research in Business and Social Sciences, 4(4), 456-469.

[14]Fellner, G. (2009). Illusion of control as a source of poor diversification: Experimental evidence. The Journal of Behavioral Finance, 10(1), 55-67.

[15]Forbes, D. P. (2005). Are some entrepreneurs more overconfident than others?.Journal of Business Venturing, 20(5), 623-640.

[16]Forlani, D. Mullins, J. (2000). Perceived risks and choices in entrepreneurs' new venture decisions. Journal of Business Venturing, 15, 305-322.

[17]Frank, H., Lueger, M., \& Korunka, C. (2007). The significance of personality in business startup intentions, start-up realization and business success.Entrepreneurship \& Regional Development, 19(3), 227-251.

[18]Gelderen, M., Thurik, R. \& Bosma, N. (2005). Success and Risk Factors in the Pre-Startup Phase. Small Business Economics 24, 365-380.

[19] Gartner, W., \& Liao, J. (2012). The effects of perceptions of risk, environmental uncertainty, and growth aspirations on new venture creation success. Small Business Economics, 39(3), 703-712.

[20]Harris, A. J., \& Osman, M. (2012). The illusion of control: A Bayesian perspective. Synthses 189(1), 29-38..

[21]Hormiga, E. \& Cruz, A. (2012). The relationship between the migration experience and risk perception: A factor in the decision to become an entrepreneur. International Entrepreneur Management Journal.

[22] Iacobucci, D. \& Duhachek, A. (2003). Advancing Alpha: Measuring reliability with Confidence. Journal of Consumer Psychology, 13(4), 478-487.

[23] Kannadhasan, M., Aramvalarthan, S., \& Kumar, B. P. (2014). Relationship among cognitive biases, risk perceptions and individual's decision to start a venture. Decision, 41(1), 87-98.

[24]Keh, H. T., Foo, M. D., \& Lim, B. C. (2002). Opportunity evaluation under risky conditions: The cognitive processes of entrepreneurs. Entrepreneurship theory and practice, 27(2), 125$148 \mathrm{~s}$ 
[25] Kerin, R. A., Varadarajan, P. R., \& Peterson, R. A. (1992). First-mover advantage: A synthesis, conceptual framework, and research propositions. The Journal of Marketing, 33-52.

[26]Kickul, J., Gundry, L. K., Barbosa, S. D., \& Whitcanack, L. (2009). Intuition versus analysis? Testing differential models of cognitive style on entrepreneurial self- efficacy and the new venture creation process.Entrepreneurship Theory and Practice, 33(2), 439-453.

[27]Langer, E. (1975). The Illusion of Control. Journal of Personality and Social Psychology, $32(2), 311-328$.

[28]Le'vesque, M. \& Minniti, M. (2006). The effect of aging on entrepreneurial behavior. Journal of Business Venturing 21, 177-194.

[29] Maldonato, M., \& Dell'Orco, S. (2011). How to make decisions in an uncertain world: heuristics, biases, and risk perception. World Futures, 67(8), 569-577.

[30] Meissner, P., \& Wulf, T. (2014). Debiasing illusion of control in individual judgment: the role of internal and external advice seeking. Review of Managerial Science, 1-19.

[31]Parhankangas, A. \& Hellström, T. (2007). How experience and perceptions shape risky behaviour: Evidence from the venture capital industry. An International Journal of Entrepreneurial Finance, 9(3), 183-205.

[32]Robinson, A. T., \& Marino, L. D. (2013). Overconfidence and risk perceptions: do they really matter for venture creation decisions?. International Entrepreneurship and Management Journal, 1-20.

[33] Shaver, K. G., \& Scott, L. R. (1991). Person, process, choice: The psychology of new venture creation. Entrepreneurship theory and practice, 16(2), 23-45.

[34] Shinnar, R. S., Giacomin, O., \& Janssen, F. (2012). Entrepreneurial perceptions and intentions: The role of gender and culture. Entrepreneurship Theory and Practice, 36(3), 465-493.

[35] Simon, M., Houghton, S. M., \& Aquino, K. (2000). Cognitive biases, risk perception, and venture formation: How individuals decide to start companies. Journal of business venturing, 15(2), 113-134

[36] Simon, M., \& Houghton, S. M. (2003). The relationship between overconfidence and the introduction of risky products: Evidence from a field study. Academy of Management Journal, 46(2), 139-149.

[37]Thompson, S. C. (1999). Illusions of control how we overestimate our personal influence. Current Directions in Psychological Science, 8(6), 187-190.

[38]Zacharakis, A. L., \& Shepherd, D. A. (2001). The nature of information and overconfidence on venture capitalists' decision making. Journal of Business Venturing, 16(4), 311-332. 